\title{
EFICÁCIA DA TRANSPOSIÇÃO DIDÁTICA DOS ALUNOS NA APRENDIZAGEM DE CÁLCULO NOS ANOS INICIAIS DOS CURSOS SUPERIORES EM ENGENHARIA E TECNOLOGIA MECATRÔNICA
}

DOI: 10.37702/2175-957X.COBENGE.2021.3369

José Adilson Silva de Jesus - jj.adilson@bol.com.br

IFSP

RUA DUQUE DE CAXIAS 861

13015-311 - CAMPINAS - SP

Lucia Scott Franco de Camargo Azzi Collet - lucia.collet@gmail.com IFSP Instituto Federal de Educação Ciência e Tecnologia de São Paulo rua Martins 851

05511-001 - São Paulo - SP

Resumo: Quando o aluno chega à faculdade, seu conhecimento está ainda fortemente marcado pelos objetos do saber cotidiano formado pelo senso comum e seria um grande equívoco desprezar essa realidade na prática pedagógica quando o professor realiza um diagnóstico dos saberes trazidos pelos alunos. Neste contexto o grande desafio do professor consiste em escolher entre as várias estratégias a que melhor se adapte e que possam contribuir na transformação do saber cotidiano do aluno e os transforme em saber escolar, preparando o caminho para a transformação do saber a ser ensinado. Assim, este artigo apresentará uma análise introdutória sobre o percurso empreendido por uma instituição de ensino superior na implantação do pensamento francês em sua forma de ensinar e como a didática da matemática pode contribuir para a educação tecnológica e seu processo de ensino-aprendizagem de logica matemática nos anos iniciais da graduação, procurando destacar uma de suas características principais: a formalização dos campos conceituais e de suas constatações práticas e teóricas na transposição do saber matemático.

Palavras-chave: Transposição didática, Contrato Pedagógico, Obstáculos epistemológicos, Situações didáticas. 


\section{EFICÁCIA DA TRANSPOSIÇÃO DIDÁTICA DOS ALUNOS NA APRENDIZAGEM DE CÁLCULO NOS ANOS INICIAIS DOS CURSOS SUPERIORES EM ENGENHARIA E TECNOLOGIA MECATRÔNICA}

\section{INTRODUÇÃO}

Didática, de uma forma simplificada, é a ciência que estuda o processo de ensinoaprendizagem. Segundo o Dicionário Houaiss da Língua Portuguesa, didática pode ser: a arte de transmitir conhecimentos; a técnica de ensinar ou a parte da pedagogia que aborda os preceitos científicos para tornar a atividade educativa mais eficiente. Como se pode observar, a didática é a ciência responsável pelo processo de ensino-aprendizagem, interligada à pedagogia.

Os desafios atuais da educação e em especial o ensino de matemática nos anos iniciais da graduação em engenharia e tecnologia na area mecatrônica, impõem aos professores uma reflexão constante de sua prática didática e da ação-reflexão-ação no ato de ensinar. Em sala de aula se deparam com demandas de ordem social, estrutural, econômica e afetiva que por vezes abalam a estrutura professor - aluno - saber - instituição de ensino.

Outro fator a ser destacado é a forma como os conteúdos estão sendo abordados em sala de aula pelo proprio professor, pois não geram significado pelos ensinamentos desenvolvidos em sala de aula para a vida prática do acadêmico e consequente compreensão dos conceitos, definições e propriedades, prevalecendo uma aula expositiva baseada na memorização de algoritmos e técnicas de resolução de exercícios que não promovem o desenvolvimento de habilidades e competências matemáticas que levem os estudantes a serem sujeitos observadores, questionadores e reflexivos em sua própria transposição do saber aprendido em matemática (SAVIANI, 1996).

Verificou-se através de observações e da prática profissional, nas aulas acompanhadas sobre Cálculo e sua aplicação na engenharia e nos relatos de outros professores da mesma instituição de ensino superior que os estudantes não conseguem relacionar o conteúdo de Cálculo com situações simples do cotidiano e de sua formação, levando alguns professores a efetuarem uma inversão ou omissão dos conteúdos do currículo para tornar o ensino mais leve ao longo da permanência do aluno na faculdade gerando o currículo nulo.

Com o objetivo de explicitar os conteúdos e as abordagens pedagógicas emergidas nas práticas dos professores nessa Instituição de Ensino Superior, este estudo foi desenvolvido através de uma abordagem quanti-qualitativa e como técnica, a implantação no ano 2019 do conceito de transposição didática por parte do titular da cadeira de Cálculo, direcionado a uma amostra composta de alunos formandos de 2019 como grupo de estudo do curso superior de Tecnologia em Mecatrônica. Portanto, este trabalho visou o conhecimento das formas como são apresentados e executados os conteúdos nas aulas de Cálculo como prática educativa no âmbito da faculdade e como se dá a transposição do saber matemático pelos alunos da instituição de ensino superior e o seu impacto na aprendizagem (CHEVALLARD, 1991). 


\section{APORTE TEORICO}

\subsection{Conteúdos e abordagens pedagógicas sobre Cálculo}

A disciplina de Cálculo analisada sob a perspectiva de seus conteúdos e abordagens, tal qual se apresentam durante todo o processo de formação do aluno é reconhecida como componente de formação crítica e que possibilita práticas que dão início a mudanças significativas na aprendizagem dos estudantes (ÁVILA; ARAÚJO, 2012).

Assim no processo de comunicação dos saberes a serem ensinados, o sistema educacional constrói um currículo onde são encontrados tópicos de matemática a serem ensinados no ensino superior que não se enquadram em demandas de formação critica necessárias à transformação da aprendizagem do aluno e paralelo a isso, assistimos a redução da carga horária do ensino de Matemática nos cursos de graduação na IES e no país sem qualquer preocupação das instituições superiores em promover um ensino crítico e de qualidade (PAIVA, 2015).

Nesse contexto se exige, cada vez mais, a capacitação do docente que não poderá mais se limitar a uma boa formação ou apenas incumbir-se de repassar o que sabe, por mais sólidos que sejam os seus conhecimentos de Matemática aos seus aprendentes, aproveitando do tempo para transformar o saber sábio, em saber a ser ensinado (BROUSSEAU, 1996a).

Este é um grande desafio para aquele que se envereda na militância da educação e ensino de matemática na universidade. Para Chevallard (1991) o saber não chega à sala de aula pronto, formatado, tal qual ele foi produzido no contexto científico. Ele passa por um processo de transformação, que implica em Ihe dar uma característica didática para que ele, o saber, para ser ensinado; isso acontece porque os objetivos da comunidade científica e da faculdade ou universidade são diferentes (PAIVA, 2015). Diante desse quadro, levantamos a seguinte questão: a transposição didática como atividade prática contribui significativamente para o processo de ensino-aprendizagem dos conceitos de Cálculo nos cursos de Tecnologia e engenharia?

De acordo com Skemp (1980), a reflexão sobre o aprendizado de matemática no âmbito da formação superior, deve levar em consideração a perspectiva docente, pois permite uma abordagem de três vertentes: sua formação continuada, o ensinoaprendizagem de matemática e o processo de avaliação da aprendizagem do aluno.

\subsection{Encaminhamento metodológico}

Este estudo foi aprovado pelo Comitê de Ética em Pesquisa do Instituto Federal de Ciência e Tecnologia de São Paulo, sob o parecer consubstanciado no 20407119.5.0000.5473 em 2019.

De acordo com o objetivo proposto, esta pesquisa se caracterizou por sua natureza como pesquisa qualiquantitativa. Seu caráter exploratório e descritivo se justifica, pois, estas pesquisas, como no pensamento de Gil $(2007$, p. 42) "[...] as que habitualmente realizam os pesquisadores sociais preocupados com a avaliação qualiquantitativa". A pesquisa qualiquantitativa se revela por sua relação dinâmica entre o mundo real e o sujeito, isto é, um vínculo indissociável entre o mundo objetivo e a subjetividade do sujeito que não pode ser traduzido em números quando o processo intelectivo é intrínseco ao sujeito da pesquisa.

A própria instituição de ensino superior foi o ambiente natural e fonte direta para coleta de dados, no caso foram convidados todos os alunos formandos no ano de 2019, num total de 64 estudantes do curso superior em tecnologia e que já haviam estudado a unidade curricular de Cálculo como formação técnica e cientifica básica para continuidade 
dos seus estudos. O pesquisador foi o canalizador da coleta de dados na busca e no cuidado de se analisar indutivamente. Foi utilizado para este primeiro artigo o seguinte instrumento para a coleta de dados: registros do PROVEI dos anos de 2014, 2015, 2017 e 2019.

O PROVEl é uma importante ferramenta de análise para definir as políticas educacionais e atender as demandas da sociedade civil frente aos desenvolvimentos tecnológicos, esta avaliação é aplicada em todas as unidades do sistema S. Libâneo (1994) ressalta que a educação em Cálculo se destaca na vivência das atividades humanas acumuladas ao longo da vida, levando em consideração a visão do homem como um ser social. Desse modo, a didática garante o fazer pedagógico no processo educativo em suas diversas dimensões (PAIS, 2015).

As abordagens do ensino de Cálculo nos cursos tecnológicos, são conhecidos também como tendências pedagógicas, são movimentos engajados na forma como os professores desenvolvem suas ações pedagógicas na condução da transposição didática do conhecimento pelo estudante. Essa prática se fundamentou em 2019 no contexto acadêmico da instituição superior como principal tendência no desenvolvimento da aprendizagem do aluno. Compartilhando com as ideias de Chevallard (1991), Bachelard (1996), Brousseau (1996a), segundo Pais (2015) as abordagens pedagógicas do ensino de Cálculo podem ser definidas como um desenvolvimento, um ato de empenho na transposição teórico-prático com o objetivo de estruturação do campo de conhecimentos que são específicos e necessários ao crescimento do aluno e sua interação à sociedade como ser crítico e construtor de ciência e tecnologia.

A transposição do saber se torna um tema de grande relevância, pois enfatiza o problema motivador da pesquisa. Ao verificar, sob a luz dos resultados apresentados pelo relatório do PROVEI nos anos referentes a 2014 e 2015 - as concepções pedagógicas dos participantes orientam a prática docente do ensino de Cálculo, verificou-se que desde a implantação do PROVEI em 2001 os objetivos e as propostas educacionais da Educação matemática, em particular Cálculo foram se modificando, e ainda hoje estas influenciam a formação do profissional e a construção e transformação do mundo ao seu redor e as práticas pedagógicas dos professores.

Para Pais (2015), "hoje se considera falsa a ideia de que um bom professor é aquele que dispõe de comunicabilidade fluente e de sólidos conhecimentos relacionados à disciplina que leciona". Os estudantes, que fazem parte do quadro discente da instituição superior, esperam que seus professores de Cálculo sejam muito mais do que meros transmissores de conhecimento ou solucionadores de problema através de algoritmos prontos para a solução da lista de exercicios.

Desta forma, repensar a formação do professor do ensino superior passou a ser uma necessidade, para se revestir das concepções filosóficas sobre a transposição didática. Diante dessa prioridade, é natural indagar pelos argumentos que justificam o enfoque conceitual na transposição didática pelo aluno e pelo professor. Sendo uma influência direta e requisito do saber rever seus pensamentos, conceitos solicitados pelo proprio saber matemático (D’AMBROSIO, 1996).

Essas ideias aparecem na definição dada por Chevallard (1991), acerca do conteúdo do conhecimento ao descrever a transposição didatica como uma transformação de um objeto de saber a ensinar a um objeto de ensino, é chamado de transposição didática. A escolha dos conteúdos de cálculo se faz principalmente através das indicações contidas nos parâmetros curriculares das faculdades, nos livros didáticos e softwares de matemática, entre outras fontes.

No plano pessoal do aluno, essa relação leva a uma dialética entre o novo e o antigo. Daí, para ocorrer a aprendizagem e sua transposição, é preciso a superação das 
contradições inerentes a essa dialética (VERGNAUD, 1996b). Para Pais (2015), o poder da contextualização do saber a ser construído modifica o fazer pedagógico do ensino e aprendizagem por parte do professor e do aluno.

Assim, os professores de matemática são desafiados em sua prática profissional a ensinar o conteúdo de Cálculo de forma dinâmica e motivadora. Nesse sentido Zabala (1998, p.81), acredita que toda atividade a partir de situações reais e funcionais, o aprendiz dê sentido àquilo que se estuda e se torne útil.

Nesse sentido a transposição ocorre por meio de um processo cognitivo em constante evolução, no qual é considerado um conjunto de saberes científicos historicamente acumulados pela sociedade (teorias da aprendizagem) e das experiências pessoais construídas pelos alunos em seu cotidiano (senso comum). Nesta perspectiva de mediação o professor definiu os objetivos de aprendizagem possibilitando aos membros da pesquisa uma progressão de suas competências e habilidades na transposição dos saberes aprendidos

\section{RESULTADOS E DISCURSSÕES}

Os resultados foram organizados a partir do eixo nomeado como Conteúdos e Abordagens Pedagógicas sobre Cálculo, conforme a estruturação dos instrumentos da pesquisa - PROVEI. Buscou-se analisar a prática pedagógica de professores de Cálculo em relação ao aprendizado alcançado pelos alunos e o desenvolvimento do raciocínio logico-matemático na transposição dos saber ensinado para o saber aprendido em relação ao desenvolvimento dos conteúdos trabalhados na disciplina em foco, enfatizando o conhecimento das abordagens teórico/metodológica que norteiam a prática pedagógica dos professores e os conteúdos de ensino utilizados no desenvolvimento e aplicação nas aulas.

O objetivo geral do PROVEI é avaliar a educação profissional oferecida pelo SENAI - SP, o desempenho dos alunos e as variáveis que fazem parte do processo ensinoaprendizagem, além de fornecer indicadores que norteiam os projetos educacionais que possam contribuir para a melhoria da qualidade do ensino ministrado (SENAI, 2018).

A concepção do PROVEI e de todos os instrumentos utilizados para o processo de avaliação têm como base as novas diretrizes para a educação profissional, no compromisso com a formação de um profissional responsável, reflexivo, que demonstre criatividade, iniciativa, conhecimento não só no que diz respeito às competências e habilidades específicas, mas que tenha como norteador a preparação de um cidadão participativo, crítico e consciente de seus direitos e deveres (MEC, 2020).

No que se refere aos Cursos Superiores de Tecnologia, o PROVEI abrange o desenvolvimento dos cursos, em relação ao alcance do perfil profissional de conclusão, e o acompanhamento dos alunos egressos em relação a sua inserção no mercado de trabalho. As estratégias estabelecidas fundamentam-se na preocupação de que outras instituições de reconhecida competência na área de avaliação conduzam o processo, a fim de que se tenha garantia de um processo avaliativo confiável, válido, fidedigno e reconhecido por todos como sendo imparcial e isento (SENAI, 2018).

\subsection{Análise de dados}

Para Barros e Lehfeld (2000) os dados apresentados tratam de um determinado momento histórico e dinâmico do conhecimento construído. Na exposição dos resultados conforme a Tabela 1, relativo aos resultados de raciocínio lógico - matemático, conforme relatório do PROVEI, demonstra que $86,1 \%$ dos participantes são proficientes ou avançados e apenas $13,9 \%$ estão no nível básico de conhecimento logico - matemático. 
Tabela 1 - C Resultados em raciocínio lógico-matemático, alunos formados em 2014

\begin{tabular}{c|c|c|c|c}
\hline GRUPO & Avançado & Proficiente & Básico & $\begin{array}{c}\text { Abaixo do } \\
\text { Básico }\end{array}$ \\
\hline $\begin{array}{c}\text { Faculdade SENAl de Tecnologia } \\
\text { Mecatrônica }\end{array}$ & $52,8 \%$ & $33,3 \%$ & $13,9 \%$ &. \\
\hline
\end{tabular}

Fonte: Relatório PROVEl entregue no dia 20 de fevereiro de 2015

Os resultados do PROVEl, aplicados aos 54 participantes previstos da Faculdade SENAI de Tecnologia Mecatrônica, foram apresentados em fevereiro de 2017. Esse instrumento avaliou os alunos formandos em 2016 no quesito de Raciocínio Lógico. $\mathrm{Na}$ exposição dos resultados conforme a Tabela 2, relativo aos resultados de raciocínio lógicomatemático, conforme relatório do PROVEI, demonstra que $84,0 \%$ dos participantes são básicos, proficientes ou avançados e apenas $16 \%$ estão no nível abaixo do básico.

Tabela 2 - Resultados em raciocínio lógico-matemático

\begin{tabular}{c|c|c|c|c}
\hline GRUPO & Avançado & Proficiente & Básico & $\begin{array}{c}\text { Abaixodo } \\
\text { Básico }\end{array}$ \\
\hline $\begin{array}{c}\text { Faculdade SENAI de } \\
\text { Tecnodogja Mecatronica (2015) }\end{array}$ & $6,0 \%$ & $30,0 \%$ & $48,0 \%$ & $16,0 \%$ \\
\hline
\end{tabular}

Fonte: Relatório do PROVEI entregue em 2017

Nos dizeres de Bachelard (1996, p.17) "o conhecimento geral serve também como um obstáculo ao conhecimento científico. Um conhecimento geral é quase fatalmente vago". A seguir no Quadro 1 apresenta-se o conjunto dos resultados comparativos entre os anos 2015, 2017 e 2019 do PROVEI em relação à evolução do conhecimento logico matemático dos alunos formandos nestes anos.

Quadro 1 - Resultados obtidos para o desempenho das Variáveis de Controle em 2015/2017/2019.

\begin{tabular}{|c|c|c|c|}
\hline \multicolumn{4}{|c|}{ Lógico-matemático } \\
\hline Nível & 2015 & 2017 & 2019 \\
\hline avançado & 8,3 & 6 & 14,8 \\
\hline proficiente & 47,2 & 30 & 70,4 \\
\hline básico & 41,7 & 48 & 14,8 \\
\hline abaixo básico & 2,8 & 16 & 0 \\
\hline
\end{tabular}

Fonte: Fonte: PROVEI $(2015,2017,2019)$ 
O gráfico comparativo da evolução da técnica de ensino implantada pela instituição como estratégia de ensino aplicada nos períodos de 2015 em relação a 2014 e 2019, usando da transposição didática como recurso educacional é visto na Figura 1.

Figura 1 - Resultados obtidos para o desempenho das Variáveis de Controle em 2015/2017/2019.

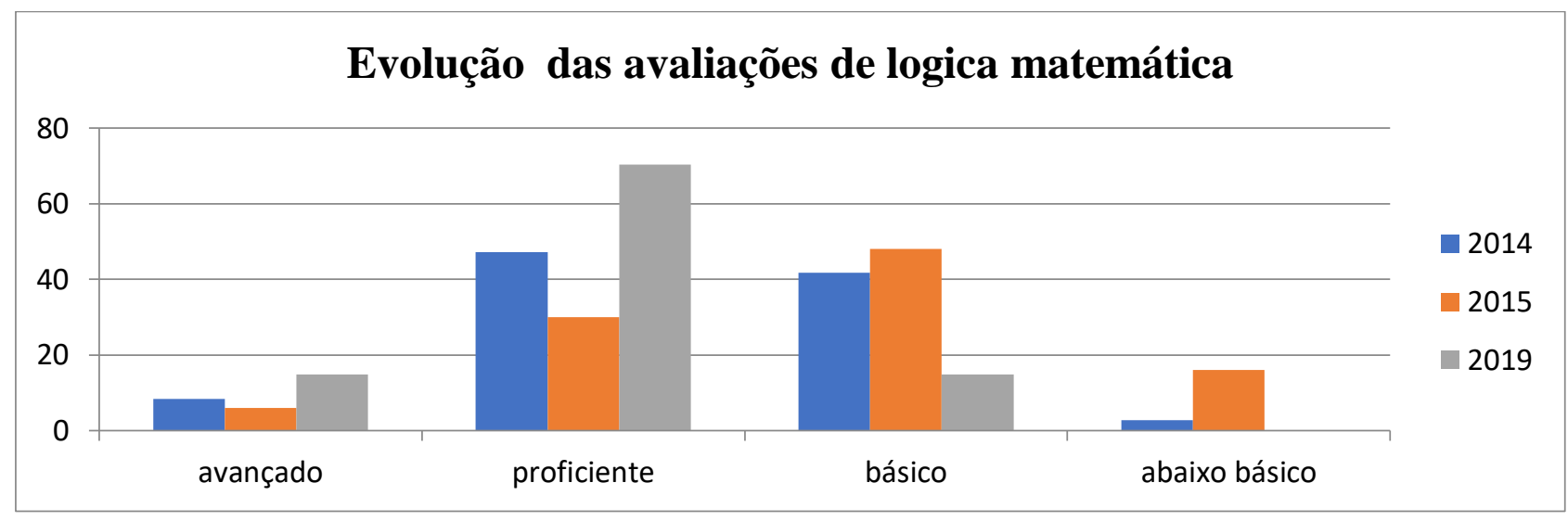

Fonte: Relatório PROVEI (2015, 2017, 2019)

Para Barros e Lehfeld (2000), toda a estratégia implantada ao longo do período, apenas esclarece o momento em que o conhecimento é construído e só é aprendido quando na realidade do aluno o mesmo pode descontruir e reconstruir o objeto de ensino em sua própria realidade, justificando a transposição didática como ferramenta de ensino e aprendizagem por parte do estudante (LUCKESI, 2002). Os níveis de satisfação com o sistema adotado pelo professor como estratégia de ensino foram estratificados pela instituição de ensino e o resultado, apresentado no Figura 2.

Figura 2 - Média Geral dos resultados obtidos na autoavaliação dos alunos do Curso Superior de Tecnologia Mecatrônica Industrial ano base 2019.

\section{Média Geral \\ Autoavaliação do Aluno}

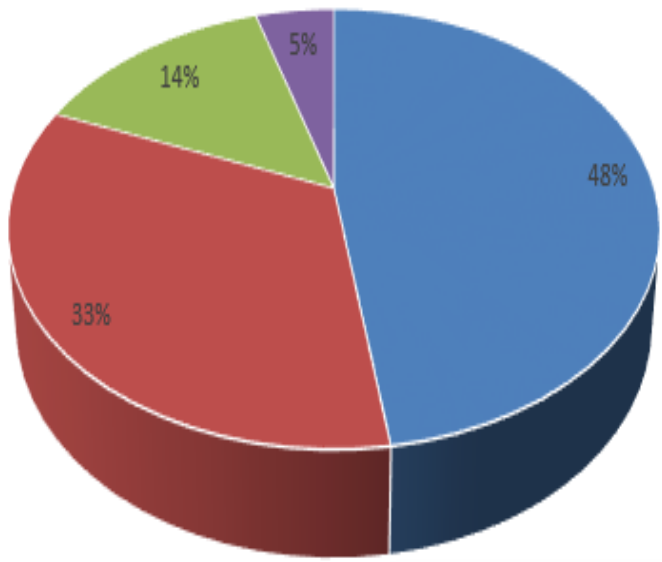

- Plenamente Satisfeito

- Satisfeito

- Parcialmente Satisfeito

- Insatisfeito

- Nẵo sei opinar

Fonte: Relatório IES/2019 
Percebe-se que em 2019, $19 \%$ dos alunos não se mostraram satisfeitos com a forma de se trabalhar com a disciplina. Quando a IES perguntou para os estudantes se eles se envolviam com as atividades da aula $73 \%$ dos mesmos responderam que sempre se envolviam com as atividades de sala de aula como visto na Figura 3.

Figura 3 - Média Geral dos resultados obtidos na autoavaliação dos alunos do Curso Superior de Tecnologia Mecatrônica Industrial..

\section{Estou sempre atento e envolvido nas} atividades da sala de aula
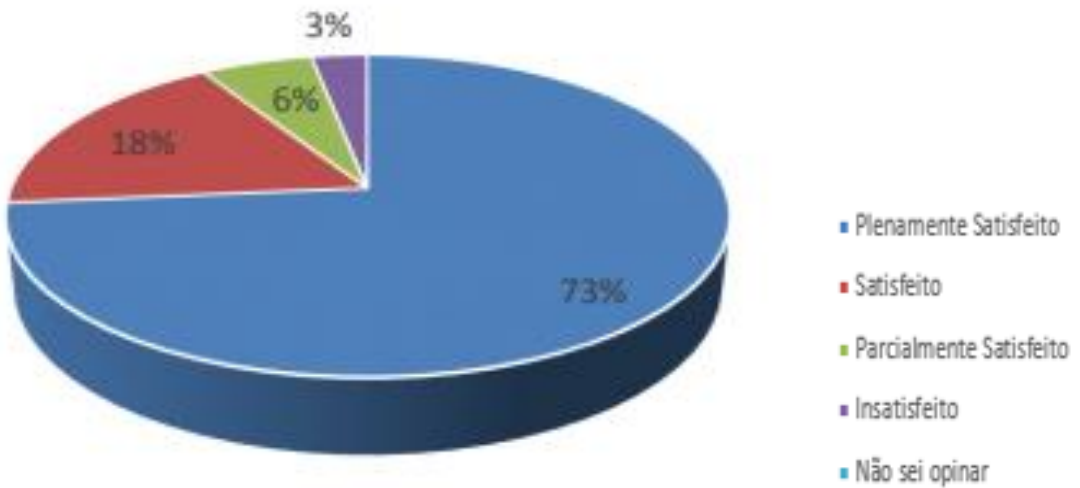

Fonte: Relatório IES/2019

Quando a IES verificou sobre os conhecimentos construídos ao longo do período utilizando a transposição didática como ferramenta de ensino os alunos forneceram como resposta na autoavaliação que mais de $50 \%$ dos mesmos apresentavam condições para acompanhar as aulas, como apresentado no Figura 4. 
Figura 4 - Média Geral dos resultados obtidos na autoavaliação dos alunos do Curso Superior de Tecnologia Mecatrônica Industrial

Possuo conhecimento anterior o suficiente para acompanhar as disciplinas

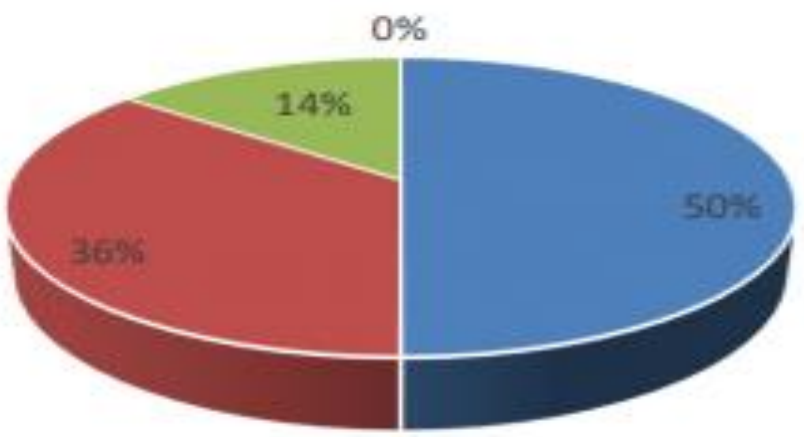

- Plenamente Satisfeito

- Satisfeito

- Parcialmente Satisfeito

- Insatisfeito

- Nẫo sei opinar

. Fonte: IES/2019

Quando indagados sobre a forma como a estratégia da transposição didática impactou em seus estudos, pontuaram afirmando que $86 \%$ deles passaram a estudar sistematicamente a disciplina de Cálculo conforme, Figura 5.

Figura 5 - Média Geral dos resultados obtidos na autoavaliação dos alunos do Curso Superior de Tecnologia Mecatrônica Industrial

\section{Estudo sistematicamente o conteúdo das disciplinas}

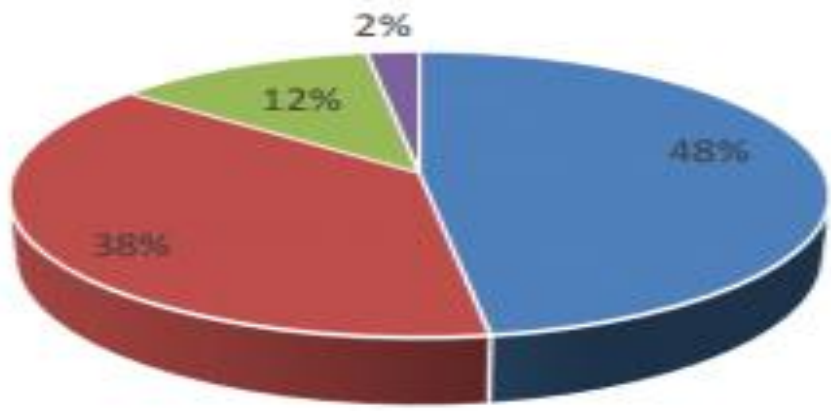

- Plenamente Satisfeito

- Satisfeito

- Parcialmente Satisfeito

- Insatisfeito

- Não sei opinar

Fonte: IES/2019

Denomine os eixos coordenados em gráficos, incluindo as respectivas unidades, sempre que aplicável. Da mesma forma, denomine colunas/linhas em tabelas, com respectivas unidades, caso aplicável. 


\section{CONSIDERAÇÕES FINAIS}

Neste artigo o estudo de Cálculo se fundamenta no conceito de transposição didática aplicado em sala de aula ao longo de dois semestres entre 2019/2020, destacamos alguns pontos de reflexão sobre a implementação dessa estratégia didática que visa a melhoria no processo de ensino-aprendizagem ativa dos estudantes sobre o conteúdo abordado e a importância do professor de Matemática em rever suas práticas pedagógicas, onde se faça presente a valorização das ações do estudante, ou seja, devem ser considerados os seus conhecimentos prévios, os erros cometidos e a partir dessas ações ressignificar conceitos que promovam uma compreensão para uma leitura do seu cotidiano num ciclo crescente de aprendizagem eficaz do ponto de vista do aprendente e da real aplicação e desenvolvimento do raciocínio logico matematica com aplicações reais no mundo do trabalho.

\section{Agradecimentos}

Gostaria de agradecer ao SENAIS- SP pelo acesso aos dados e possibilidades em usar um método de ensino aprendizagem nas turmas de graduação. Ao mesmo tempo compartilhar com o meio academico e com professores os frutos colhidos para serem degustados como alimento final à nossa labuta diária como professores. Ao IFSP pela oportunidade de conhecer outras estradas e formas diferentes de percorrê-la.

\section{REFERÊNCIAS}

BACHELARD, G. A formação do espírito científico. Rio de Janeiro: Contraponto, 1996. BARROS, A. J. S; LEHFELD, N. A. S. Fundamentos de metodologia científica: um guia para a iniciação científica. São Paulo: Pearson Makron Books, 2000.

BROUSSEAU, G. Fundamentos e Métodos da Didáctica da Matemática. In: BRUN, J. Didática das Matemáticas. Tradução de: Maria José Figueiredo. Lisboa: Instituto Piaget, 1996a. p. 35-113.

CHEVALLARD, Y. La tranposición didáctica: Del saber sábio al saber enseñado. Traduzida por Claudia Gilman. Editora Aique: Buenos Aires. 1991.

D'AMBROSIO, U. Educação Matemática da Teoria à Prática. Coleção Perspectivas em Educação Matemática. Campinas: Papirus, 1996.

GIL, A. C. Métodos e Técnicas de Pesquisa Social. 5 ed. São Paulo: Atlas, 2007.

http://portal.mec.gov.br/index.php?option=com docman\&view=download\&alias=112681rces002-19\&category slug=abril-2019-pdf\&ltemid=30192 acesso em jun. 2020 http://portal.mec.gov.br/sesu/arquivos/pdf/DocDiretoria.pdf

LUCKESI, C. C. Avaliação da aprendizagem escolar. 13ํe․ São Paulo: Cortez, 2002. 
PAIS, L. C. Didática da Matemática; uma análise da influência francesa. 3. ed.; 1. reimp. — Belo Horizonte: Autêntica Editora, 2015.

PROVEI - Programa de Avaliação da Educação Profissional do SENAI/SP. 2014, 2015, 2017, 2019.

Relatório da CPA 2018 - Faculdade SENAI de Tecnologia Mecatrônica - SENAI, 2020.

SAVIANI, D. Escola e democracia. 30.ed. Campinas. SP: Autores Associados, 1996.

SEVERINO, A. J. Metodologia do trabalho científico. 23. ed. rev. e atual. São Paulo: Cortez, 2007.

SKEMP, R. Psicologia del aprendizaje de las matemáticas. Trad. Gonzalo Gonzalvo Mainar. Madrid: Ediciones Morata, S. A. 1980.

VERGNAUD, G. (1996b). A trama dos campos conceituais na construção dos conhecimentos. Revista do GEMPA, Porto Alegre, № 4: 9-19.

ZABALA, A. A prática educativa: como ensinar. Porto Alegre: ArtMed, 1998.

\title{
EFFECTIVENESS OF STUDENT LEARNING TRANSPOSITION IN LEARNING CALCULATION IN THE INITIAL YEARS OF HIGHER COURSES IN ENGINEERING AND TECHNOLOGY IN MECHATRONICS
}

\begin{abstract}
When the student arrives at college, his knowledge is still strongly marked by the objects of everyday knowledge formed by common sense and it would be a great mistake to ignore this reality in pedagogical practice when the teacher makes a diagnosis of the knowledge brought by the student. In this context, the great challenge of the teacher is to choose between the various strategies that best adapt and that can contribute to the transformation of the student's daily knowledge and transform them into school knowledge, preparing the way for the transformation of the knowledge to be taught. Thus, this article will present an introductory analysis on the path taken by a higher education institution in the implementation of French thought in its teaching and how mathematics didactics can contribute to technological education and its teaching-learning process of mathematical logic in the initial years of graduation, trying to highlight one of its main characteristics: the formalization of conceptual fields and their practical and theoretical findings in the transposition of mathematical knowledge.
\end{abstract}

Keywords: Didactic transposition. Pedagogical contract. Epistemological obstacles. Didactic situations. 